\title{
Pyrolysis-mass spectrometry for rapid classification of oysters according to rearing area
}

\author{
M. Cardinal ${ }^{1 *}$, C. Viallon ${ }^{2}$, C. Thonat ${ }^{2}$ and J.-L. Berdagué ${ }^{2}$ \\ ${ }^{1}$ Laboratoire Génie Alimentaire, IFREMER, rue de l'île d'Yeu, BP 21105, 44311 Nantes Cedex 3, France \\ ${ }^{2}$ Laboratoire Flaveur, Station de Recherches sur la Viande, INRA de Theix, \\ 63122 St-Genès-Champanelle, France
}

\begin{abstract}
Current concern for the safety and traceability of food, as well as the desire of oyster farmers, for marketing reason, to emphasise the geographical origin of their production, requires new methods to make possible a real product identification. In this study, 181 oyster samples were analysed to determine their origin area. These samples were collected in nine French rearing areas at four different times of the year (spring, summer, and the beginning and end of autumn) and from four to eight sites in each area to provide a variability parameter. Analysis of fingerprints after Curie point pyrolysis-mass spectrometry, by an artificial neural network gave a mean classification rate of $89 \%$. Although the technique requires further improvements, it appears to be a useful discriminative tool for rapid identification of an oyster production area.
\end{abstract}

Keywords. Oyster - classification - pyrolysis-mass spectrometry - production area - neural network.

\section{Introduction}

In 1996, France was the leading European producer of the Pacific oyster Crassostrea gigas (Thunberg), with an estimated output of 152,000 metric tonnes [1]. This species has become virtually the single crop of shellfish farmers, regardless of the production area in France.

French producers wish to emphasise regional values not only to upgrade their production and avoid changes in industrial rearing activities that might involve product standardisation, but also to avoid degradation of the coastal environment. Accordingly, an effort is being made to develop techniques allowing a more precise description of product characteristics, at a national and international level. Moreover, in the present context in which the health aspects of food are a main concern for consumers, tools are needed to identify the origin of products and ensure food safety and traceability.

Viable techniques have not been reported for characterising shellfish origin. A global analysis of flesh components (proteins, carbohydrates and lipids) is not useful for this purpose and much of the studies deal with the identification of volatile compounds in different shellfish [2-6] but do not take origin effect into account. Three years ago, the French Research Institute for the Exploitation of the Sea (IFREMER) undertook studies in this field and analysed the oyster volatile fraction by gas chromatography and mass spectrometry [7] but did not succeed in identifying specific molecules in relation to origin.
More recent technique like polymerase chain reaction (PCR) could be proposed to answer the problem of origin identification but for the moment, works deal with the discrimination between closely related Pacific oyster species [8] or the genetic differentiation between populations of Crassostrea angulata and Crassostrea gigas [9] but did not try to classify the same oyster specie, from different areas of production.

The purpose of the present study was to test the technique of Curie point pyrolysis (an automated technique) coupled to mass spectrometry (Cp-PyMS) for discriminating oysters collected, for one year, from main production areas. This rapid technique provides global "fingerprints" for the matrix food product (carbohydrates, lipids and proteins). These fingerprints are obtained by filtering the positive ions resulting from thermal fragmentation of the product matrix (after pyrolysis), followed by electronic impact fragmentation.

This technique has already proved to be a very powerful tool for solving problems of classification and identification in various sectors of the food industry, such as olive oils [10], meat products [11] or bacteria from fish products [12].

\section{Materials and methods}

\section{Samples and sampling procedure}

Oysters (C. gigas) were sampled in nine French rearing areas (Fig. 1): two along the English Channel in eastern (EN) and western Normandy (WN); six on the Atlantic 


\section{Original articles}

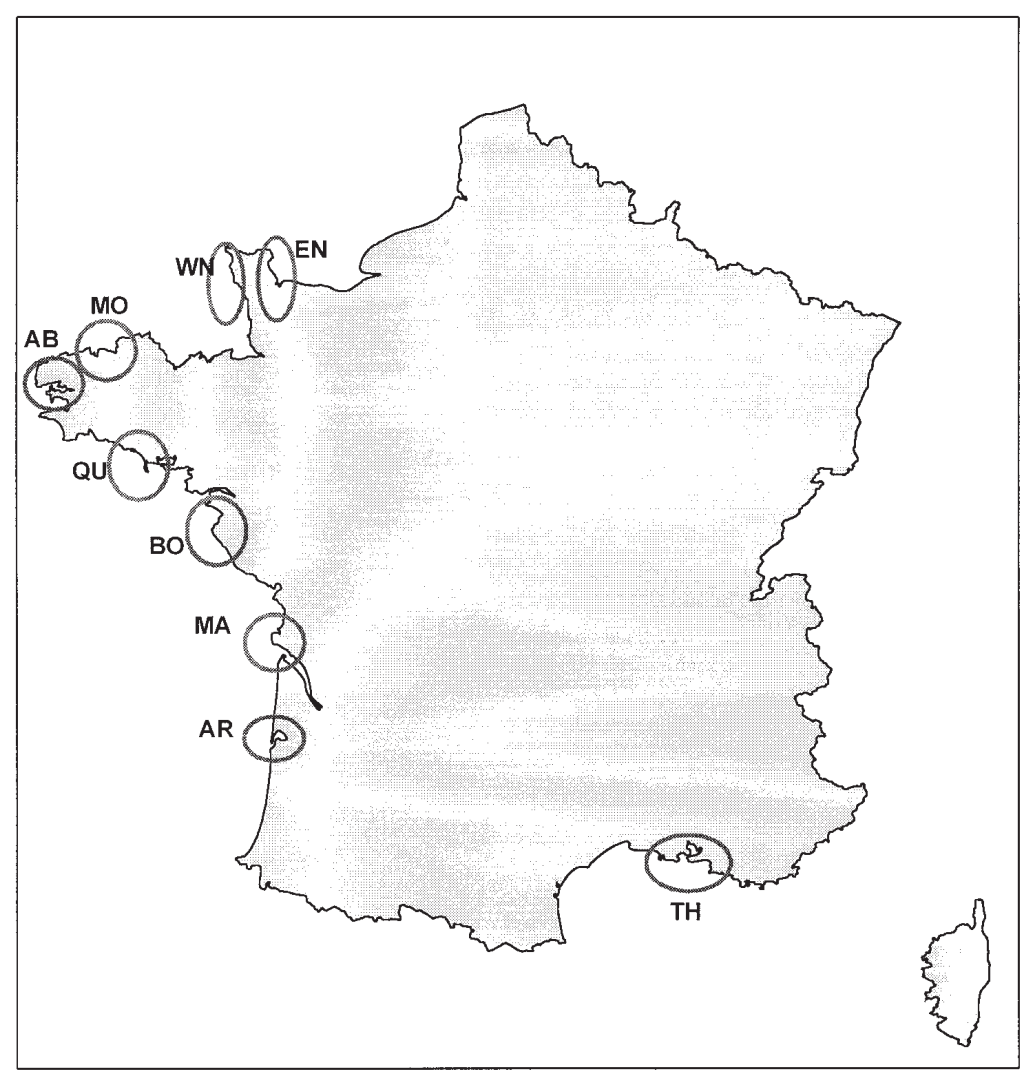

Figure 1. Oyster sampling areas along the French coast. Identification of rearing areas and number of sampled sites:

$\mathrm{AB}=$ Abers (end of the Brittany peninsula), 4 sites; $\mathrm{AR}=$ Arcachon bay, 5 sites;

$\mathrm{BO}=$ Bourgneuf bay, 5 sites; MA = MarennesOléron Bay, 8 sites; MO = Morlaix (Northern Brittany), 5 sites; EN = Eastern Normandy, 5 sites; $\mathrm{WN}=$ Western Normandy, 5 sites; $\mathrm{QU}=$ Quiberon bay, 5 sites; $\mathrm{TH}=$ Thau Lagoon, 5 sites.

All the sites were sampled in spring, summer, at the beginning and at the end of autumn except for one site of MO not sampled in summer and for six sites from MA where samples were not taken at the end of autumn. Total number of samples: 181 .

coast, i.e. northern Brittany near Morlaix (MO), at the end of the Brittany peninsula near the Abers area (AB), Quiberon Bay (QU), Bourgneuf Bay (BO), Marennes-Oléron Bay (MA), and Arcachon Bay (AR); and one along the Mediterranean coast at Thau Lagoon (TH). Various sites (4 to 8), corresponding to different producers, were analysed within each area to ensure a better representation of each rearing area. Samples were obtained in 1997 during spring, summer and the beginning and end of autumn. The oysters studied had been reared for at least one year on the site and weighed between 50 and $80 \mathrm{~g}$. A sample of thirty oysters was collected directly from each shellfish pond. The flesh of these oysters was pooled, freeze-dried and ground. Samples were stored at ambient temperature, around $20{ }^{\circ} \mathrm{C}$, in completely filled flasks and protected from humidity and air until analysis by Cp-PyMS.

\section{Sample preparation for Cp-PyMS}

Four grams of oyster powder were added to $50 \mathrm{ml}$ of distilled water and mixed for $10 \mathrm{~s}$ using an Ultra Turrax. After addition of $1 \mathrm{ml}$ of $\mathrm{KOH}(1 \mathrm{~N})$, the solution was stirred and allowed to settle for $5 \mathrm{~min}$. Two microlitres of a liquid sample were pipetted (Ependorf) and deposited on clean ironnickel foil (SS-Scientific Ltd., Hellingly, UK), which was then dried in an oven (Prolabo ST 15) at $150{ }^{\circ} \mathrm{C}$ for $5 \mathrm{~min}$. Two replicates were performed for each sample. Foils were introduced into silica pyrolysis tubes (Maillères Ets, Aubière, France) as described by Berdagué et al. [11].

\section{Pyrolysis-mass spectrometry}

A Horizon Instruments mass spectrometer (Cp-PyMS RaPyD 400) was used in this study. The tube containing the foil was heated at $530{ }^{\circ} \mathrm{C}$ for $3 \mathrm{~s}$ during Curie-Point pyrolysis, using a temperature rise time of $0.6 \mathrm{~s}$ chosen to provide balanced fragmentation of carbohydrates, lipid and protein fractions. The pyrolysate then entered an expansion chamber heated at $160{ }^{\circ} \mathrm{C}$ and was diffused through a molecular beam tube to the ionisation chamber of the mass spectrometer. To minimise secondary fragmentation of the pyrolysate, low-voltage electron impact ionisation $(33.9 \mathrm{eV})$ was used. Non-ionised molecules were retained in a cold trap cooled by liquid nitrogen. The ionised fragments were focused by the electrostatic lens of a set of source electrodes, accelerated and then directed into a quadrupole mass filter. The ions were separated by the quadrupole according to their mass on charge ratio, detected and amplified with an electron multiplier. The mass spectrometer scanned the ionised pyrolysate 65 times during pyrolysis. Data were collected over the $\mathrm{m} / \mathrm{z}$ range (50 to 240 Dalton). Spectral information was recorded for the ion count of the individual masses scanned and the total ion count of each analysed sample. The mass spectrometer was calibrated using the 
chemical standard perfluorokerosene (Ref. number 32, 8359; Sigma-Aldrich).

\section{Data analysis}

For each mass spectrum, individual mass fragments were standardised in percentages of the total ion count in order to avoid any influence of sample size.

Fragmentation of oyster deposits by Cp-PyMS provided 191 mass fragments (49<m/z<241 Daltons) and 362 observations (181 different oyster samples $\times 2$ replicates). Then, the Cp-PyMS spectra were normalised and a mean mass spectra was computed for each oyster sample. Finally, data were pooled in a $X_{\text {PyMs }}$ matrix containing 191 variables and 181 observations (181 oyster samples).

\section{Selection of input variables}

The selection of a limited subset $X_{\text {selected }}$ of relevant variables extracted from the $X_{\text {PyMs }}$ matrix, was performed by stepwise discriminant analysis according to the nine oyster production areas (stepdisc procedure/stepwise method) [13]. This selection was performed to limit the number of input variables and avoid an overfitting of the data during Artificial Neural Network training.

\section{Classification by Artificial Neural Networks (ANNs)}

An $X_{\text {final }}$ matrix, including the $X_{\text {selected }}$ matrix and the qualitative "production season" variable, was used to train ANNs [14] in order to classify oysters according to their nine origins. The algorithm used was standard back-propagation [15]. The structure of the network used to classify oyster samples (chosen in preference to other structures tested) consisted of three layers containing 20 inputs (19 selected variables of the $X_{\text {selected }}$ matrix and the production season variable), one hidden layers containing 12 nodes, and 9 outputs $\left(X_{\text {classes }}\right.$ matrix). The $X_{\text {classes }}$ matrix was a disjunctive table containing nine binary variables for the nine classes of oysters. Finally, the architecture of the network was 20-129. Network training consisted of calculating the weights of the connections between the network nodes, which minimise the difference between the output nodes (or $X_{\text {predicted }}$ matrix) and the $X_{\text {classes }}$ matrix. Computations of the networks during cross-validation steps were stopped after 400 epochs. Crossvalidations were of the "leave-one-out" type. They consisted in successively removing each of the 181 observations from the $X_{\text {Final }}$ matrix and predicting its class (rearing area) from the remaining 180 observations. In total, 181 different training runs were carried out from the 181 different sub-populations of 180 observations. Results of the classification of each observation by these 181 neural networks was presented in a confusion matrix. The tuning of each network training involved a learning rate of 0.30 , back-propagation momentum of 0.10 , and a regular decrease in additional noise from 0.10 to 0.05 . The activation function was logistic: $1 / 1+\mathrm{e}^{-x}$, with output in the range $(0,+1)$.

\section{Results and discussion}

Spectra were expressed as a percentage of ion total abundance. The shape more than the intensity of the signal was taken into account in order to minimise the effect of sample deposit.

The selection of variables by the "stepdisc/stepwise selection procedure" allowed 19 ions to be retained as statistical variables among the 191 in the pyrolysis spectra. The mass of these ions, ranked according to their entry order in discrimination functions, were $m / z=74,98,106,67,79,126$, 81, 62, 139, 86, 109, 88, 95, 104, 58, 57, 53, 116, and 131 . This selection is not optimal, but offered a simple high-performance compromise to reduce the number of input variables for neural networks.

As the ions produced by PyMS resulted from two successive fragmentations (thermal fragmentation of the matrix and electronic impact fragmentation of pyrolysates), it was difficult or impossible to relate the masses of the fragments to the molecular species analysed. Thus, the spectra were considered as "fingerprints" of the oysters with no attempt made to identify the chemical origin of the differences observed between oysters.

The use of Cp-PyMS fingerprints to classify oysters according to their geographical origin was quite efficient since 161 out of 181 oyster samples used in validation $(89.0 \%)$ were correctly classified according to their origin, regardless of season. Moreover, the confusion matrix (Tab. I) indicates that 16 of the 20 wrongly classified samples $(8.8 \%)$ could be identified as belonging to another geographical area, whereas only four samples (2.2\%) were impossible to attribute to one of the nine study areas (for these four samples, the nine output predicted values were close to zero).

The results obtained allowed the samples to be classified according to rearing area, but did not provide an explanation of the factors involved in this discrimination. Some mistakes in classification might have been due to a very similar composition in different oysters and especially to the planktonic feeding effect. The physiological state, particularly the spawning period, which differed from one area to another, may also have influenced response and classification. For future studies, it might be useful to consider additional parameters as spawning state, oyster compounds and environmental quality for a better interpretation of classification results.

From a practical point of view, the time required for manual preparation of each sample, placing it on foil and inserting the foil into the silica pyrolysis tube was about $2 \mathrm{~min}$. Automatic analysis of the 362 samples was performed in two days: 236 samples the first day and 126 the second. In total, measurements lasted approximately 9 hours, at a rate of one analysis every $1.5 \mathrm{~min}$.

Changes in total abundance of mass spectra during the 362 analyses showed a regular decrease in the signal during the analyses performed on day 1 and 2 of measurement (Fig. 2). This signal drift can be explained by the rate of 


\section{Original articles}

Table I. Confusion matrix.

Predicted rearing areas

\begin{tabular}{|c|c|c|c|c|c|c|c|c|c|c|c|}
\hline $\begin{array}{l}\text { Areas of } \\
\text { Origin }\end{array}$ & $\begin{array}{c}\text { Sample } \\
\text { size }\end{array}$ & $U N^{l}$ & $A B^{2}$ & $A R^{2}$ & $B O^{2}$ & $M A^{2}$ & $M O^{2}$ & $E N^{2}$ & $W N^{2}$ & $T H^{2}$ & $Q U^{2}$ \\
\hline $\mathrm{AB}$ & 16 & & $\begin{array}{c}13 \\
81.0 \%\end{array}$ & 1 & & & 1 & & 1 & & \\
\hline AR & 20 & & & $\begin{array}{c}18 \\
90.0 \%\end{array}$ & 1 & 1 & & & & & \\
\hline $\mathrm{BO}$ & 20 & 1 & & & $\begin{array}{c}17 \\
85.0 \%\end{array}$ & & & & & & 2 \\
\hline MA & 25 & 1 & & 1 & & $\begin{array}{c}23 \\
92.0 \%\end{array}$ & & & & & \\
\hline MO & 20 & 1 & & 1 & & & $\begin{array}{c}18 \\
90.0 \%\end{array}$ & & & & \\
\hline $\mathrm{EN}$ & 20 & & & & & & & $\begin{array}{c}20 \\
100 \%\end{array}$ & & & \\
\hline WN & 20 & & & & & 1 & 2 & & $\begin{array}{c}17 \\
85.0 \%\end{array}$ & & \\
\hline $\mathrm{TH}$ & 20 & & & & & & & & & $\begin{array}{c}20 \\
100 \%\end{array}$ & \\
\hline QU & 20 & 1 & & & 2 & 2 & & & & & $\begin{array}{c}15 \\
75.0 \%\end{array}$ \\
\hline
\end{tabular}

1: Unclassified samples

2 : production areas with number and percentage of samples correctly classified

$\mathrm{AB}=$ Abers (end of Brittany peninsula), $\mathrm{AR}=$ Arcachon bay, $\mathrm{BO}=$ Bourgneuf bay, $\mathrm{MA}=$ Marennes-Oléron Bay, $\mathrm{MO}=$ Morlaix (Northern Brittany), EN Eastern Normandy, WN Western Normandy, TH = Thau Lagoon, QU = Quiberon bay.

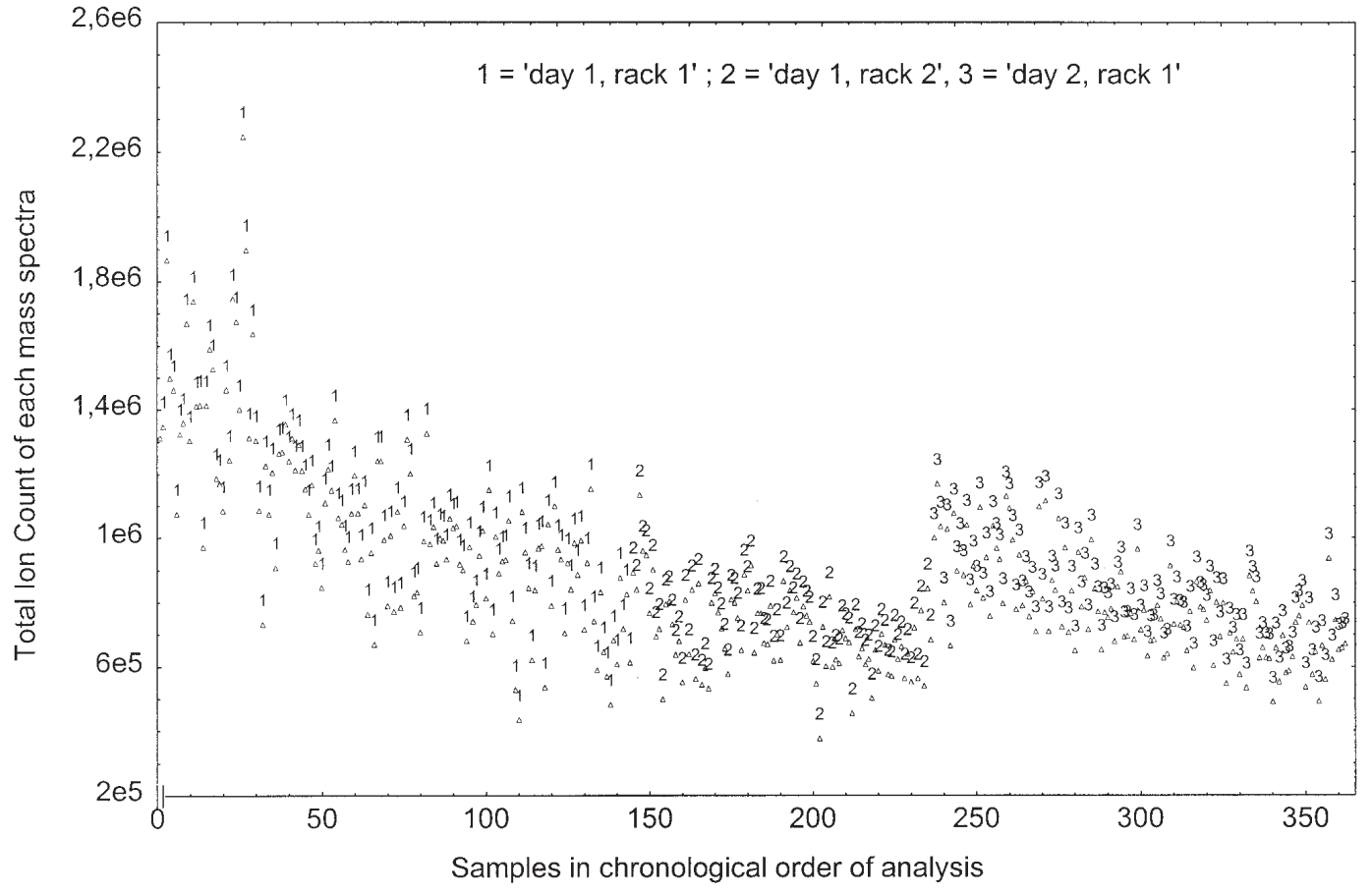

Figure 2. Decrease of total ion count of mass spectra during analyses. 
analyses, i.e. an increase of pollution in the pyrolysate transfer area could have affected vacuum quality and produced a gradual loss of instrument sensitivity. Fortunately this loss had no visual effect on the global profile of mass spectra. To minimise this problem, it may be necessary to limit the quantity of material used for pyrolysis (estimated at $500 \mathrm{ng}$ in our experiment) and/or slow the rate of analyses.

\section{Conclusion}

The Curie point Pyrolysis Mass Spectrometry appears to provide a powerful tool for rapid identification of the geographical origin of oysters. Improvements in sample preparation conditions (analysis of fresh material), the pyrolysis step (limitation of the quantity of material used and the rate of analyses to avoid loss of equipment sensitivity during repeated analyses) should allow the discriminative power of pyrolysis-mass spectrometry analyses to be increased.

A new series of measurements taking possible annual variations into account would be useful to confirm these results. Tests also need to be conducted to determine the time required for an oyster to take the fingerprint of a new geographical area after a transfer. Finally it will be necessary to ensure that the tool is suitable for routine identification of oyster origin.

\section{Acknowledgements}

The authors are grateful to the IFREMER coastal laboratories for sampling and oyster preparation, especially Port en Bessin, Morlaix, La Trinité, Bouin, La Tremblade, Arcachon and Palavas, and to Joseph Mazurie for the sampling design and Philippe Goulletquer, Jean-Pierre Baud and Régis Baron for their helpful comments.

\section{References}

1. Goulletquer, P. Proceedings of the 29th Annual Conference of the Shellfish Association of the United Kingdom, London 1920 May, 1998, 69-80.

2. Ronald, A. P.; Thomson, W. A. B. J. Fish Res. Bd Canada 1964, 21, 1481-1487.

3. Josephson, D.B.; Lindsay, D.A.; Stuiber, D.A. J. Food Sci. 1985, 50, 5-9.

4. Lindsay, R.C. Food Review International 1990, 6, 437-455.

5. Josephson, D.B. Seafood. In: Volatile compounds in food and beverages, MAARSE H. (Eds.), New York, Marcel Dekker, Vol. 6, 1991, pp 179-202.

6. Piveteau, F. Ph.D. Thesis, Université de Nantes, March 1999.

7. Anonymous, Rapport interne IFREMER DRV/RA/RST 98-07, 1998, 300 p.

8. Banks, M.A.; Hedgecock, D.; Waters, C. Mol. Mar. Biol. Biotechnol. 1993, 2(3), 129-136.

9. Boudry, P.; Heurtebise, S.; Collet, B.; Cornette; F.; Gérard, A. J. of Exp. Mar. Biol. and Ecol. 1998, 226(2), 279-291.

10. Goodacre, R.; Kell, D., B.; Bianchi, G. J. Sci. Food Agric. 1993, 63, 297-307.

11. Berdagué, J.-L.; Rabot, C.; Bonneau, M., Sciences des Aliments 1996, 16, 425-433.

12. Dalgaard, P.; Manfio, G.P.; Goodfellow, M. Zbl. Bakt. 1997, 285, 157-168.

13. SAS Institute Inc, In SAS/STAT User's Guide, Release 6.03 Edition; 1988, pp 359-447.

14. STATISTICA A comprehensive system for statistics, graphics and application development, Version 5.1 for Windows; Statsoft: Charenton-le-Pont, France, 1997.

15. McClelland, J.L.; Rumelhart, D.E. In: Explorations in parallel distributed processing. A handbook of models, programs and exercices; Cambridge MIT Press, MA. 1988. 